\title{
A Scale-Free Dynamic Model for District Heating Aggregated Regions
}

\author{
Costanza Saletti ${ }^{\mathrm{a}^{*}}$, Nathan Zimmerman ${ }^{\mathrm{b}}$, Mirko Morini ${ }^{\mathrm{a}, \mathrm{c}}$, \\ Konstantinos Kyprianidis ${ }^{\mathrm{b}}$, Agostino Gambarotta ${ }^{\mathrm{a}, \mathrm{c}}$
}

\author{
${ }^{a}$ Department of Engineering and Architecture, University of Parma, Parco Area delle Scienze \\ 181/A, 43124 Parma, Italy \\ ${ }^{\mathrm{b}}$ Department of Automation in Energy and Environment, School of Business, Society and \\ Engineering, Mälardalen University, Box 883, Västerås, 72123, Sweden \\ ${ }^{\mathrm{c}}$ Center for Energy and Environment (CIDEA), University of Parma, Parco Area delle Scienze 42, \\ 43124 Parma, Italy \\ * Corresponding author: costanza.saletti@unipr.it
}

\begin{abstract}
District heating networks have become widespread due to their ability to distribute thermal energy efficiently, which leads to reduced carbon emissions and improved air quality. The characteristics of these networks vary remarkably depending on the urban layout and system amplitude. Moreover, extensive data about the energy distribution and thermal capacity of different areas are seldom available. Design, optimization and control of these systems are enabled by the availability of fast and scalable models of district heating networks. This work addresses this issue by proposing a novel method to develop a scale-free model of large-scale district heating networks. Starting from coarse data available at the main substations, a physics-based model of the system aggregated regions is developed by identifying the heat capacity and heat loss coefficients. The model validation on the network of Västerås, Sweden, shows compatibility with literature data and can therefore be exploited for system design, optimization and control-oriented applications. In particular, the possibility to estimate the heat storage potential of network regions allows new smart management strategies to be investigated.
\end{abstract}

Keywords: District Heating Network; reduced-order model; building heat capacity; scalability; gray-box model 


\section{Introduction}

The European Union has recently established long-term objectives to reduce greenhouse gas emissions and, potentially, achieve climate neutrality by 2050 , by engaging all sectors of the economy and society [1]. These goals require a complete transformation of the energy system, in which the heating and cooling sector plays a significant role in terms of consumption and potential for decarbonization. Indeed, thermal energy distribution to households and industries can be accomplished by District Heating Networks (DHNs) in a more efficient way compared to individual devices, since they consist of supplying heat produced in centralized plants to the end-users by means of a network of pipelines. Hence, these networks enable the utilization of multiple energy resources, such as renewables and waste heat from industrial processes [2]. Moreover, DHNs reduce the number of emission sources, as they move the energy production devices in centralized sites outside cities and residential zones. For this reason, populated areas, where the reduction in carbon dioxide emissions and the consequent improvement in air quality are paramount, are ideal for extending this technology to a large scale. DHNs are already the dominant heat supply system in some countries such as Sweden, where they meet about half of the global thermal demand. According to Sernhed $e t$ al. [3], in this country a large number of research projects is being carried out to further reduce energy consumption in these systems and to promote their application to other areas. Research and innovation actions on these topics are widespread across all other European countries. This is confirmed by 58 projects funded by the European Union as part of the Horizon 2020 Framework Programme and which focus on smart district heating systems [4].

However, a widespread application of these systems can be challenging, as the design, management and control of DHNs vary significantly depending on several factors:

- the geographical area, which defines the typical climate and, therefore, the specific demand; 
- the system scale, which defines the global demand and the required level of detail for its representation (i.e. in small-scale systems, the consumers can be modeled individually, while in large-scale systems this would require significant effort);

- $\quad$ the system configuration and layout;

- the availability of data and information, e.g. consumption, building type and system temperatures.

In order to overcome the aforementioned drawbacks, it is necessary to have reliable models of DHNs, which can be used for multiple investigations, e.g. design studies, optimization algorithm and controloriented applications.

In the literature, there is an increasing number of papers that focus on the development of simulation models [5] of the production, distribution and consumption sides of DHNs. Some works investigate the potential role as thermal storage of the water in the networks which, depending on size, comprise a large number of pipelines. For instance, Kouhia et al. [6] show that, when the grid is used as storage by allowing the supply temperature to vary freely within certain constraints, the heat provision costs are reduced by $2 \%$. Moreover, supply temperature optimization is regarded as a promising development to by addressed. Sartor and Dewallef [7] propose to increase the temperature supplied to the DHN up to $140{ }^{\circ} \mathrm{C}$ (technical constraint) to mitigate the payback time of additional storage tanks and to improve the operation of the Combined Heat and Power (CHP) plants, which are the most common production units in these systems. The significant increase in heat loss is counterbalanced by a 0.2 EUR/MWh decrease in heat cost due to the avoided use of the backup boilers. Other papers present models of the end-users connected to the network. In particular, a study by Dominković et al. [8] proposes a building simulation model coupled with a linear optimization model of the DHN in Sønderborg, Denmark, to analyze the benefits of preheating the thermal mass of part of the connected residential building stocks, which are collected in six archetypes. Hence, data such as floor area, construction age and internal heat capacity are required to replicate the analysis. 
One of the most relevant studies regarding the thermal inertia of buildings in DHNs is proposed by Kensby et al. [9], which presents an actual pilot test performed on five multifamily residential buildings in order to investigate their potential to function as short-term energy storage. The selected consumers are equipped with data acquisition devices and subjected to five test control cycles, consisting of different periods of charging and discharging. The results are scaled up in order to provide an estimation of the heat storage potential for DHN. Indeed, the authors conclude that an energy amount of $0.1 \mathrm{kWh}$ per square meter of heated floor area causes variations in indoor temperature lower that $0.5{ }^{\circ} \mathrm{C}$ in heavy buildings. In a subsequent article [10], these empirical tests are combined with an energy balance model and a unit commitment problem to compare the use of the building thermal capacity with that of centralized storage tanks. In this case, the former is divided into shallow storage (i.e. radiators and indoor air) and deep storage (i.e. structural elements), which show different rates of heat transfer. This additional level of complexity, which requires the estimation of the model parameters of these types of storage, might hinder its application to other contexts.

Similarly, other studies investigate both the network and consumers as potential heat storage means. It is oftentimes specified that the latter is more feasible, but the essential individual analysis of the DHN and building construction [11] can be time-consuming and difficult to source. An integrated approach to the operational optimization of DHNs that includes all three types of storage (i.e. hot water tanks, thermal inertia of the pipelines and thermal inertia of the buildings), but not real-time control, is proposed in [12].

Despite these considerations, the state-of-the-art research lacks simplified models of the consumers that can be applied to large-scale DHN without the need to carry out extensive and detailed investigation of network characteristics and individual building data, which can be time-consuming and expensive. 
This paper proposes a novel reduced-order, scale-free model of DHN end-users that can be built with a limited amount of data available from the system substations. The main aggregated parameters of the clusters of buildings connected to the network are evaluated with a physics-based approach, in order to estimate their heat capacity and heat losses. The model is identified with basic data concerning the water mass flow rate and temperatures provided by the main substation heat exchangers. The network characteristics can then be used to carry out further analysis, such as calculating the storage potential of different areas of the network or optimize heat distribution. The investigation regards the district heating network of the city of Västerås, in central Sweden. Nonetheless, the method is applicable to substations supplying entire regions (without detailed information on the utilization units) as well as individual buildings.

\section{Model development}

The research method used in this paper to develop the simplified dynamic model of aggregated heating networks is detailed in this section as an application to the main regions of the large-scale DHN of the city of Västerås, in central Sweden. The further extension of the method to different systems and applications is straightforward.

The Västerås DHN is supplied by a centralized production site, comprising a waste-to-energy cogeneration plant, back-up boilers and thermal energy storage tanks. Six peripheral regions within the area are supplied by the DHN: Surahammar, Skultuna, Rönnby, Tillberga, Barkarö and Hallstahammar. Historical data from the main substation heat exchangers of the six external regions for the years 2016 to 2018 are available regarding the water mass flow rate, supply temperature and return temperature on an hourly basis. This dataset is analyzed and preprocessed in order to eliminate odd values and outliers (Section 2.1). Then, it is used to identify the relevant coefficients of a simplified model that represents an aggregated set of consumers (i.e. aggregated region) and considers both their heat loss and heat capacity (Section 2.2). The obtained values are compared with specific 
coefficients per unit of heated area or heated volume, typically related to individual buildings connected to DHNs, available in the literature $[12,13]$. This represents the model validation with literature parameters which is reported in Section 3.

\subsection{Data preprocessing}

In Sweden, district heating providers are required to measure heat consumption through smart meter devices installed in the substations. The availability of data makes it possible to identify the usual behavior of the system to a greater extent and to investigate more efficient management strategies. For instance, Calikus et al. [14] perform a data-driven investigation of the heat load pattern of two district heating networks in southern Sweden in order to provide a better understanding of typical and atypical customer behavior depending on their category. However, it is still common that in other contexts the data acquisition devices are only installed in given sections of the network. Hence, as mentioned in Section 1, it is beneficial to investigate methods that can be implemented in networks where the end-users are not monitored at an individual building-scale.

Moreover, since the data are collected automatically [14], there might be connection issues resulting in missing data or values that are not significant in the dataset. Hence, the data are cleaned by means of a preprocessing phase that eliminates missing sensor readings.

In this work, the available data are gathered from the main substation heat exchangers of the six external regions of the Västerås DHN during the period January 2016-May 2019, with a resolution of one hour. The dataset includes the following quantities:

- water mass flow rate of the primary side of the substation heat exchanger, $\dot{m}$;

- $\quad$ supply and return temperature of the primary side of the substation heat exchanger, $T_{\mathrm{S}}$ and $T_{\mathrm{R}}$, respectively;

- outdoor temperature, $T_{\text {ext. }}$ 
Therefore, the thermal power actually transferred to each region $\dot{Q}$, which covers the heat demand of the aggregated end-users, can be calculated according to the energy balance in Eq. (1):

$$
\dot{Q}=\dot{m} \cdot \mathrm{c} \cdot\left(T_{\mathrm{S}}-T_{\mathrm{R}}\right)
$$

where $c$ is the water specific heat capacity.

This analysis aims to create a model that is suitable to exploit the heat capacity of the consumers when there is a thermal demand. Thus, the acquisitions related to the heating seasons (i.e. from October of each year to March of the following year) are extracted from the initial dataset.

The days with acquisitions that show one of the following features are eliminated from the dataset:

- the thermal power is zero or negative;

- the supply temperature is lower than a given threshold (i.e. $40{ }^{\circ} \mathrm{C}$ );

- the difference of temperature at the primary side of the substation is lower than a given threshold (i.e. $10{ }^{\circ} \mathrm{C}$ );

- the outdoor temperature is higher than $19^{\circ} \mathrm{C}$.

The latter cases are excluded because they represent a condition - in which the heat demand is not relevant - far from the typical pattern of a heating season in Sweden.

\subsection{Model identification}

The data are visualized in order to identify load profiles and typical behaviors. Generally, for each day of the heating season it is possible to identify a double peak behavior, in which the increase in heat load in the early morning is followed by a maintenance period and then a second evening peak.

The approach is similar to that proposed by Guelpa et al. [13], who optimize the DHN of Turin, Italy by (i) adopting a clustering approach in order to identify the relevant characteristics of the connected buildings and (ii) scheduling the switch-on of the heating system to shave the peak load. The authors 
calculate the coefficients that characterize a compact model based on the energy balance of each building starting from seasonal data.

In the present work, without other information concerning the individual end-users and the network-specific configurations, the dataset related to each region is used to identify a simplified dynamic model that represents the sum of the buildings of the given area as a single aggregated consumer. For this purpose, the region is considered as a system with a given mass at a uniform temperature $T$, which is an equivalent representation of the energy content of the aggregated consumer. A simplified and reliable representation of the aggregated consumer has to consider the main factors that affect its thermal behavior, which are (i) the heat dissipation through the envelope - influenced by the difference between indoor and outdoor temperatures - and (ii) the thermal power supplied by the DHN. The model is represented by the thermal balance in Eq. (2):

$$
\frac{d T}{d t}=-\frac{U}{C}\left(T-T_{\mathrm{ext}}\right)+\frac{1}{C} \dot{Q}
$$

where $T_{\text {ext }}$ is the outdoor temperature and $\dot{Q}$ is given by Eq. (1). The aggregated heat transfer coefficient $U$ and the aggregated heat capacity $C$ of the region are the relevant parameters of the model. The procedure for their calculation from the available data is described in the following sections.

\subsubsection{Calculation of the heat transfer coefficient}

In order to calculate the heat transfer coefficient $U$ of the model described above, it is assumed that the indoor thermal conditions of the aggregated consumer are constant and, thus, the variation of $T$ over time is not significant. Eq. (3) is obtained and calculated for each data point of the dataset, by assuming that $T$ is equal to $21{ }^{\circ} \mathrm{C}$ [15]. The mean of the obtained values gives the estimation of the average coefficient $U$. 


$$
U=\frac{\dot{Q}}{\left(T-T_{\mathrm{ext}}\right)}
$$

Four different methods are compared to challenge the reliability of the assumption:

1. All data relating to the heating seasons are selected for the calculation.

2. The data corresponding to the hours from 10 a.m. to 6 p.m. on weekdays are selected for the calculation. Indeed, the maintenance phase in which the indoor comfort conditions of the buildings are kept constant typically corresponds to late morning and afternoon. In residential dwellings this maintenance phase can last longer, however, the present model includes different types of end-users, such as commercial and education buildings. Hence, the assumption of constant indoor temperature is presumably more reliable during the hours of the day mentioned above, in order to include all users.

3. The data corresponding to the days on which the percentage variation between maximum and minimum daily thermal power is close to the percentage variation between maximum and minimum indoor-outdoor temperature difference are selected for the calculation. This means that the daily variation of the outdoor temperature can potentially justify the daily variation of the heat load as well as the initial assumption.

4. Eq. (3) is integrated over each day and the average over the heating season is selected.

The results obtained with the methods explained above for the six regions of the network are reported in Table 1. The average values and standard deviations (absolute and relative to the average) are also shown. It is possible to notice that the standard deviation is lower than $8 \%$ in all cases, so the methods can be considered almost equivalent. Methods 1 and 4 tend to return lower values of the coefficients. This might be due to the fact that it is not consistent with the initial assumption (i.e. constant indoor temperature) to consider all the daily measurements. The coefficients obtained with method 2 are used to proceed with the model development, since they are expected to better comply with that assumption. Moreover, it is more convenient to overestimate the coefficient that influences the heat 
losses to the environment, in order to reduce the risk of adopting new management solutions that do not comply with the comfort requirements.

Table 1. Calculation of the heat transfer coefficient $U$ (in $\mathrm{kW} /{ }^{\circ} \mathrm{C}$ ) for all six regions with four different methods. The average value and standard deviation for each region are also shown.

\begin{tabular}{cccccccc}
\hline Region & Method 1 & Method 2 & Method 3 & Method 4 & Average & $\begin{array}{c}\text { Standard } \\
\text { deviation }\end{array}$ & $\begin{array}{c}\text { Standard } \\
\text { deviation [\%] }\end{array}$ \\
\hline Surahammar & 367.23 & 390.19 & 391.95 & 366.81 & 379.0 & 13.9 & 3.7 \\
Skultuna & 219.38 & 239.47 & 250.39 & 218.73 & 232.0 & 15.6 & 6.7 \\
Rönnby & 99.29 & 101.83 & 101.87 & 99.26 & 100.6 & 1.5 & 1.5 \\
Tillberga & 177.04 & 200.25 & 201.62 & 176.60 & 188.9 & 13.9 & 7.4 \\
Barkarö & 114.30 & 116.96 & 117.02 & 114.22 & 115.6 & 1.6 & 1.4 \\
Hallstahammar & 1046.0 & 1104.7 & 1106.6 & 1046.0 & 1075.8 & 34.5 & 3.2 \\
\hline
\end{tabular}

\subsubsection{Calculation of the heat capacity coefficient}

Starting from the estimation of the equivalent heat transfer coefficient calculated above, the heat capacity $C$ is evaluated by assuming that the indoor temperature of the aggregated region is subjected to periodic variations over the days. Indeed, in most buildings in Sweden the indoor temperature set-points are kept at $21^{\circ} \mathrm{C}$ during the day and $17^{\circ} \mathrm{C}$ during the night [15]. The typical daily profile of the indoor building temperature is subjected to an increase up to approximately the former temperature and then a decrease to the latter. It is reasonable to assume that the evolution of the region equivalent temperature over each day resembles this profile.

The coefficient of each region is estimated by solving the following optimization problem:

- The equivalent indoor temperature of the aggregated consumer is simulated with the input data over a defined period as a function of $C$.

- The temperature has to be maintained within the set-point boundaries (i.e. between $17^{\circ} \mathrm{C}$ and $21^{\circ} \mathrm{C}$ ). Since it also has to show a variation during each day, the maximum and minimum 
temperatures reached during each day shall lie within given acceptability bands (e.g. $20{ }^{\circ} \mathrm{C}$ to $22{ }^{\circ} \mathrm{C}$ and $17^{\circ} \mathrm{C}$ to $19{ }^{\circ} \mathrm{C}$ for the maximum and minimum temperatures, respectively).

- A penalty is added to the cost function if the constraints described in the previous point are not met.

- The cost function is minimized and, therefore, the value of $C$ that leads to the most reasonable behavior of the system is obtained.

This procedure is adopted to guarantee that the value of $C$ is coherent with the expected daily periodical variation. A low value of heat capacity leads to sharp oscillations in the temperature and, consequently, to the underestimation of the storage potential of the given region. On the contrary, a high value of the coefficient leads to a nearly constant temperature behavior and to the overestimation of the storage capability. This, in turn, leads to the underestimation of the effects on the end-users of some management choices.

\section{Model validation}

The results of the estimation of the heat transfer coefficient $U$ and heat capacity coefficient $C$ are reported in Table 2. These parameters can be compared and validated with literature data if converted to specific parameters per unit of heated space.

Since the total heated area of the regions of the Västerås DHN is unknown, this is estimated based on the energy statistics published by the Swedish Energy Agency [16]. The document reports the values of the average yearly energy consumption per square meter of heated surface for different Swedish counties. The ratio between the total yearly consumption of a given region and the average yearly consumption gives the estimation of the total heated surface of that region. The model coefficients calculated above are then scaled with this estimation of the heated area. By assuming an average height of the heated environments of $3 \mathrm{~m}$, it is possible to further scale the values and obtain the specific coefficients per unit of heated volume. 
Table 2. Estimation of the heat transfer coefficient and heat capacity coefficient for the six external regions of the Västerås district heating network.

\begin{tabular}{ccc}
\hline Region & $U\left[\mathrm{~kW}^{\circ} \mathrm{C}^{-1}\right]$ & $C\left[\mathrm{~kJ}^{\circ} \mathrm{C}^{-1}\right]$ \\
\hline Surahammar & 390.19 & $13.750 \cdot 10^{6}$ \\
Skultuna & 239.47 & $11.974 \cdot 10^{6}$ \\
Rönnby & 101.83 & $5.350 \cdot 10^{6}$ \\
Tillberga & 200.25 & $10.550 \cdot 10^{6}$ \\
Barkarö & 116.96 & $3.875 \cdot 10^{6}$ \\
Hallstahammar & 1104.7 & $39.350 \cdot 10^{6}$ \\
\hline
\end{tabular}

The statistics for the region of Västmanland, where Västerås is located, present the average yearly heat consumption $Q_{\text {avg }}$ between $135 \mathrm{kWh} / \mathrm{m}^{2}$ and $165 \mathrm{kWh} / \mathrm{m}^{2}$ [16]. The sensitivity analysis of the specific coefficients $U_{V}$ and $C_{V}$ with this parameter is shown in Figure 1. The characteristic time of each region $\tau$, obtained as the ratio between $C$ and $U$, is also represented.

The coefficients $U_{V}$ and $C_{V}$ calculated in [13] for individual buildings in the Turin DHN are around $0.85 \mathrm{~W} /\left(\mathrm{m}^{3}{ }^{\circ} \mathrm{C}\right)$ and $5 \cdot 10^{4} \mathrm{~J} /\left(\mathrm{m}^{3}{ }^{\circ} \mathrm{C}\right)$, respectively. The characteristic times vary significantly depending on building type: most values are around $7 \cdot 10^{4} \mathrm{~s}$, while some are even smaller than 5 . $10^{4} \mathrm{~s}$.

The estimation performed in this work is slightly lower than the literature values, however, the order of magnitude is the same. The fact that the characteristic times are comparable shows that the heat transfer and heat capacity coefficients are coherent. Moreover, it is worth stating that the literature values have been obtained for individual buildings in the city of Turin, which is characterized by old multi-story dwellings. The regions of Västerås are likely to be characterized by an aggregation of newer or more energy-efficient dwellings, therefore, a lower loss coefficient can be reasonably expected. This is confirmed by a research stating that the average temperature loss of Italian houses - when the indoor and outdoor temperatures are $20{ }^{\circ} \mathrm{C}$ and $0{ }^{\circ} \mathrm{C}$, respectively - is $1.5^{\circ} \mathrm{C}$, while in 
Sweden this parameter drops to $1.2^{\circ} \mathrm{C}$ [17]. Hence, lower values of the heat loss coefficient for networks in Sweden compared to Italy are justified by the different characteristics of the connected buildings. Additionally, another paper [11] reports that the values of the internal heat capacity of light-weight buildings drop to $8 \cdot 10^{4} \mathrm{~J} /\left(\mathrm{m}^{2}{ }^{\circ} \mathrm{C}\right)$, which corresponds to around $3 \cdot 10^{4} \mathrm{~J} /\left(\mathrm{m}^{3}{ }^{\circ} \mathrm{C}\right)$ and is coherent with the analysis in Figure 1.

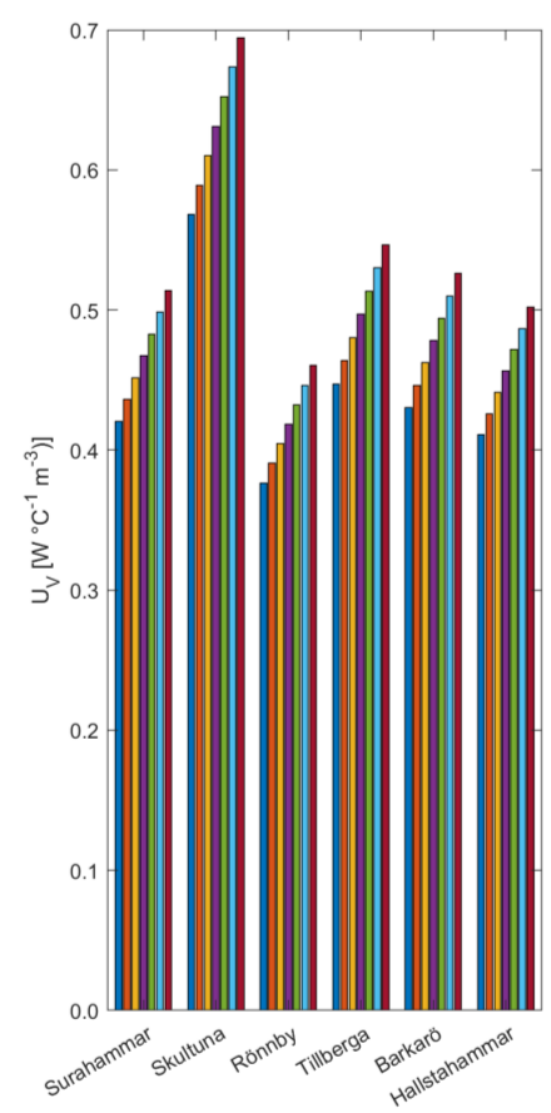

(a)

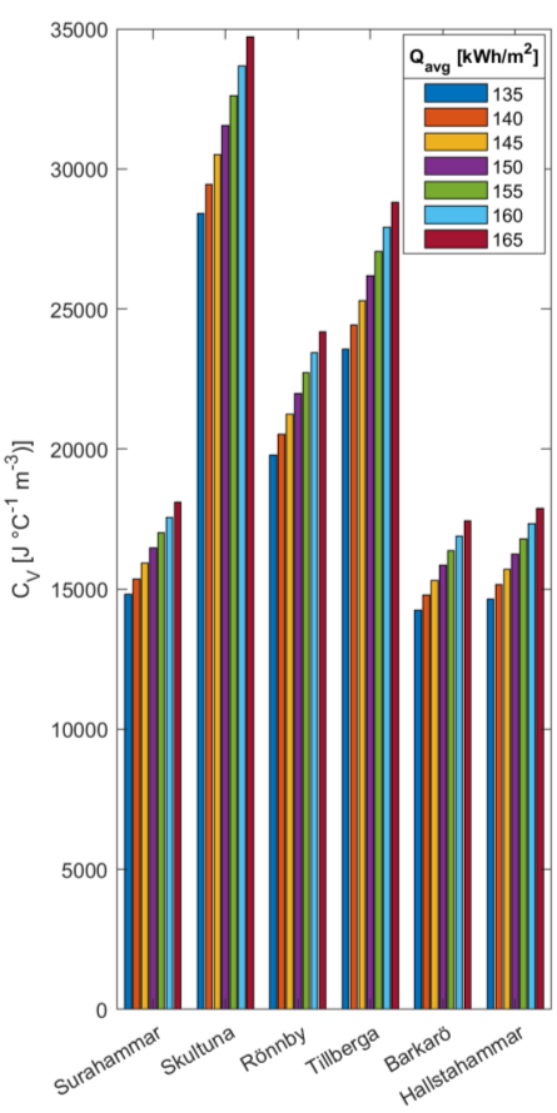

(b)

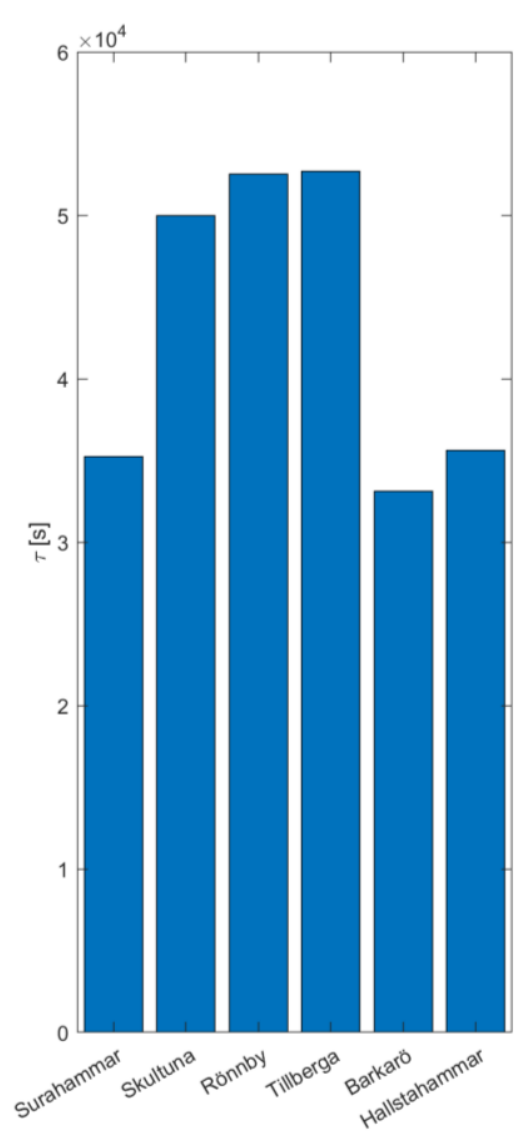

(c)

Figure 1. Specific coefficients of heat transfer (a) and heat capacity per unit of heated volume (b) and characteristic time (c): external regions of the Västerås district heating network.

A further check with the considerations drawn in [12] is represented in Figure 2. According to the authors, the aggregated Demand Side Management actions performed (i.e. storage of thermal energy in consumer capacity) are limited to $1.4 \%$ of the total heat demand [12] in the period analyzed. The potential daily heat storage obtained with this assumption can be compared with that obtained with the model proposed in this work - considering an acceptable building temperature variation of $\pm 0.5^{\circ} \mathrm{C}$. The results obtained are comparable also in this case. 


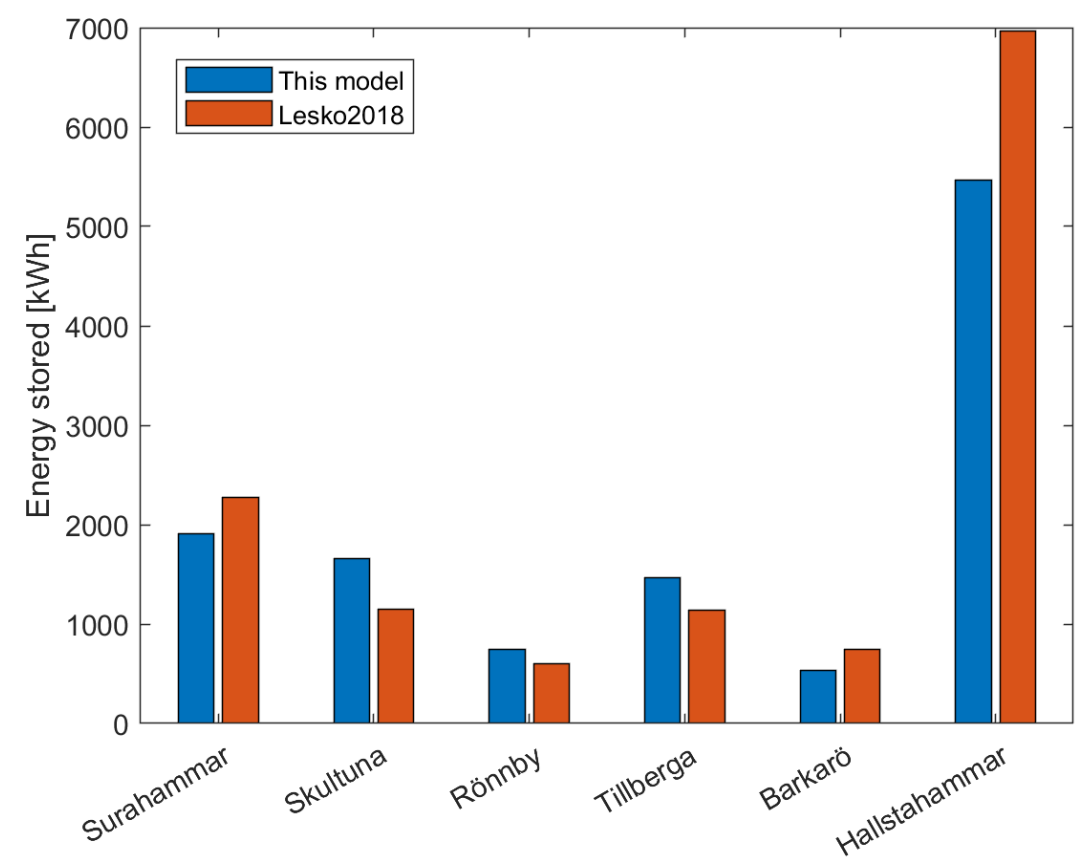

Figure 2. Energy stored in the region thermal mass: comparison between this model and that proposed by Leśko et al. [12].

With this validation, the procedure and the aggregated models of the six regions of the Västerås network is assessed. In order to perform a preliminary test of its feasibility, a simple application in the Simulink environment is developed [18]. The supply of the thermal power - available from the historical data - from the substation heat exchanger to the model of the aggregated consumer is simulated and the equivalent indoor temperature of the aggregated consumer is then visualized.

A spot result concerning the region of Surahammar for the heating season from October 2018 to March 2019 is depicted in Figure 3. It can be noticed that the indoor temperature is maintained around $21{ }^{\circ} \mathrm{C}$ and is subjected to daily variations of $2{ }^{\circ} \mathrm{C}$ to $4{ }^{\circ} \mathrm{C}$, which is reasonable and compatible with the expected profile. Additional weekly periodical variations in the temperature evolution can be noticed and justified by the different behavior typically observed on weekends and during holidays. As a matter of fact, on these days commercial, industrial or tertiary-sector end-users seldom require heating. This has an influence on the temperature of the aggregated region, which is a representation of its energy content. Similar results are obtained for other regions and other heating seasons. 


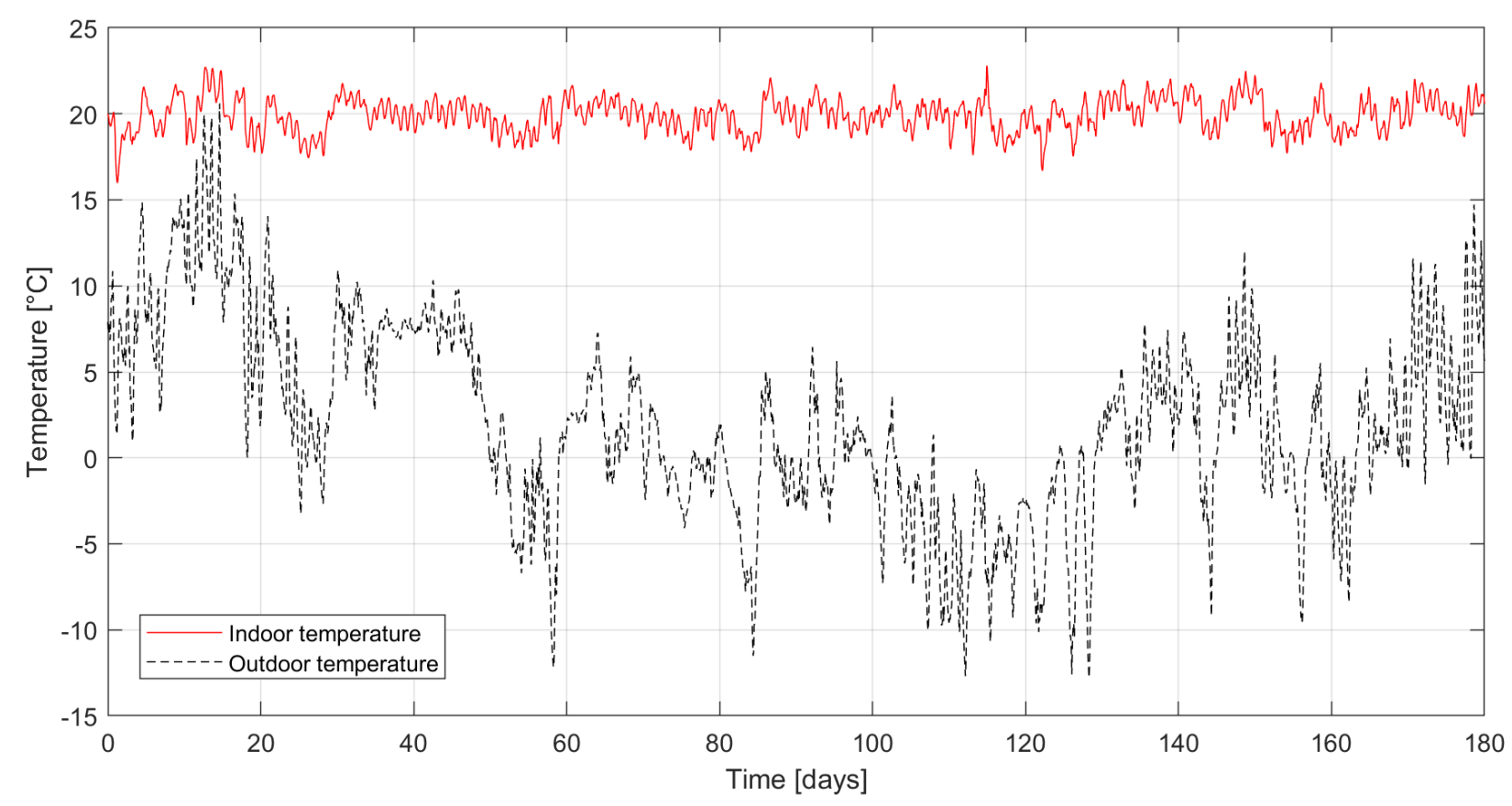

Figure 3. Preliminary test of the model performed with a Simulink application [29]. The results of the indoor temperature refer to the region of Surahammar during the heating season from October 2018 to March 2019.

\section{Conclusions}

The currently available models of large-scale district heating networks do not allow the thermal capacity of the connected end-users to be efficiently included in system optimization and control. Indeed, typically the inclusion of thermal mass relies either on indoor temperature monitoring (which is rarely available in large-scale heating networks) or on a detailed knowledge of the characteristics of the buildings (e.g. time constants, materials and size) and, therefore, this is time-consuming and daunting for large-scale applications. This work proposed a method that can be readily applied using a potentially small amount of data to which district heating providers typically have access. Starting from the data available at the main substation heat exchangers of the peripheral regions of the district heating network of Västerås, Sweden, a physics-based equivalent model of each aggregated region was identified and verified with data from the literature and simulations. The model was exploited to evaluate the aggregated storage potential of the regions and will be the key element of smart optimization and control strategies. These features will be investigated in future studies to provide 
valuable tools for the digitalization of district heating and its transitions to more sustainable and smart energy systems.

\section{Acknowledgements}

This work was supported by the "DISTRHEAT - Digital Intelligent and Scalable conTrol for Renewables in HEAting neTworks" project, which received funding in the framework of the joint programming initiative ERA-Net Smart Energy Systems' focus initiative Integrated, Regional Energy Systems, with support from the European Union's Horizon 2020 research and innovation programme under grant agreement No 775970. It was also supported by the "Bando Leonardo da Vinci 2019 Azione 2" funded by the Italian Ministry of Education, University and Research (MIUR).

The authors would also like to thank their industrial partner Mälarenergi AB for providing the data of the district heating network of Västerås.

\section{References}

[1] Communication from the Commission to the European Parliament, the European Council, the Council, the European Economic and Social Committee, the Committee of the Regions and the European Investment Bank. A Clean Planet for all a European strategic long-term vision for a prosperous, modern, competitive and climate neutral economy. COM/2018/773. Brussels, 28/11/2018. Available at: https://eur-lex.europa.eu/legalcontent/EN/TXT/?uri=CELEX:52018DC0773 [accessed 10/06/2020]

[2] Werner S. International review of district heating and cooling. Energy 2017;137:617-631. https://doi.org/10.1016/j.energy.2017.04.045

[3] Sernhed K, Lygnerud K, Werner S. Synthesis of recent Swedish district heating research. Energy 2018;151:126-132. https://doi.org/10.1016/j.energy.2018.03.028 
[4] Saletti C, Morini M, Gambarotta A. The Status of Research and Innovation on Heating and Cooling Networks as Smart Energy Systems within Horizon 2020. Energies 2020;13(11):2835. https://doi.org/10.3390/en13112835

[5] Hoyo Arce Id, Herrero López S, López Perez S, Rämä M, Klobut K, Febres JA. Models for fast modelling of district heating and cooling networks. Renewable and Sustainable Energy Reviews 2018;82: 1863-1873. https://doi.org/10.1016/j.rser.2017.06.109

[6] Kouhia M, Laukkanen T, Holmberg H, Ahtila P. District heat network as a short-term energy storage. Energy 2019;177:292-303. https://doi.org/10.1016/j.energy.2019.04.082

[7] Sartor K, Dewallef P. Integration of heat storage system into district heating networks fed by a biomass CHP plant. Journal of Energy Storage 2018;15:350-358.

https://doi.org/10.1016/j.est.2017.12.010

[8] Dominković DF, Gianniou P, Münster M, Heller A, Rode C. Utilizing thermal building mass for storage in district heating systems: Combined building level simulations and system level optimization. Energy 2018;153:949-966. https://doi.org/10.1016/j.energy.2018.04.093

[9] Kensby J, Trüschel A, Dalenbäck JO. Potential of residential buildings as thermal energy storage in district heating systems - Results from a pilot test. Applied Energy 2015;137:773-781. https://doi.org/10.1016/j.apenergy.2014.07.026

[10] Romanchenko D, Kensby J, Odenberger M, Johnsson F. Thermal energy storage in district heating: Centralised storage vs. storage in thermal inertia of buildings. Energy Conversion and Management 2018;162:26-38. https://doi.org/10.1016/j.enconman.2018.01.068

[11] Turski M, Sekret R. Buildings and a district heating network as thermal energy storages in the district heating system. Energy and Buildings 2018;179:49-56.

https://doi.org/10.1016/j.enbuild.2018.09.015 
[12] Leśko M, Bujalski W, Futyma. Operational optimization in district heating systems with the use of thermal energy storage. Energy 2018;165:902-915.

https://doi.org/10.1016/j.energy.2018.09.141

[13] Guelpa E, Deputato S, Verda V. Thermal request optimization in district heating networks using a clustering approach. Applied Energy 2018;228:608-617.

https://doi.org/10.1016/j.apenergy.2018.06.041

[14] Calikus E, Nowaczyk S, Sant'Anna A, Gadd H, Werner S. A data-driven approach for discovering heat load patterns in district heating. Applied Energy 2019;252:113409.

https://doi.org/10.1016/j.apenergy.2019.113409

[15] Nageler P, Heimrath R, Mach T, Hochenauer. Prototype of a simulation framework for georeferenced large-scale dynamic simulations of district energy systems. Applied Energy 2019;252:113469. https://doi.org/10.1016/j.apenergy.2019.113469

[16] Energistatistik för flerbostadshus 2016 (Energy statistics for multi-dwelling buildings in 2016). Sveriges officiella statistik. Swedish Energy Agency ES 2017:4. ISSN 1654-7543 [available in Sweden]

[17] Guidebook. UK homes losing heat up to three times faster than European neighbours. February 20, 2020. Available at https://www.tado.com/t/en/uk-homes-losing-heat-up-to-three-times-fasterthan-european-neighbours/ [accessed on 10/06/2020]

[18] Cadau N, De Lorenzi A, Gambarotta A, Morini M, Saletti C. A Model-in-the-Loop application of a Predictive Controller to a District Heating system. Energy Procedia 2018;148:352-359. https://doi.org/10.1016/j.egypro.2018.08.088 


\section{Nomenclature}

C

aggregated heat capacity coefficient $\left[\mathrm{kJ}{ }^{\circ} \mathrm{C}^{-1}\right]$

c water specific heat capacity $\left[\mathrm{kJ} \mathrm{kg}^{-1}{ }^{\circ} \mathrm{C}^{-1}\right]$

$\dot{m}$

mass flow rate $\left[\mathrm{kg} \mathrm{s}^{-1}\right]$

$\dot{Q}$

thermal power $[\mathrm{kW}]$

$Q_{\text {avg }}$

average heat consumption $\left[\mathrm{kWh} \mathrm{m}^{-2}\right]$

$T$

temperature $\left[{ }^{\circ} \mathrm{C}\right]$

$t$

time [s]

$U$

aggregated heat transfer coefficient $\left[\mathrm{kW}^{\circ} \mathrm{C}^{-1}\right]$

$\tau$

characteristic time $[\mathrm{s}]$

Subscripts

ext

outdoor

R

return

S

supply

V

specific per unit of heated volume

Acronyms

CHP Combined Heat and Power

DHN District Heating Network 